\title{
Modality-Spanning Deficits in Attention-Deficit/ Hyperactivity Disorder in Functional Networks, Gray Matter, and White Matter
}

\author{
๑Daniel Kessler, ${ }^{1}{ }^{\oplus}$ Michael Angstadt, ${ }^{1}$ Robert C. Welsh, ${ }^{1,2}$ and ${ }^{\circledR}$ Chandra Sripada ${ }^{1}$ \\ ${ }^{1}$ Department of Psychiatry and ${ }^{2}$ Department of Radiology, University of Michigan, Ann Arbor, Michigan 48109
}

\begin{abstract}
Previous neuroimaging investigations in attention-deficit/hyperactivity disorder (ADHD) have separately identified distributed structural and functional deficits, but interconnections between these deficits have not been explored. To unite these modalities in a common model, we used joint independent component analysis, a multivariate, multimodal method that identifies cohesive components that span modalities. Based on recent network models of ADHD, we hypothesized that altered relationships between large-scale networks, in particular, default mode network (DMN) and task-positive networks (TPNs), would co-occur with structural abnormalities in cognitive regulation regions. For 756 human participants in the ADHD-200 sample, we produced gray and white matter volume maps with voxel-based morphometry, as well as whole-brain functional connectomes. Joint independent component analysis was performed, and the resulting transmodal components were tested for differential expression in ADHD versus healthy controls. Four components showed greater expression in ADHD. Consistent with our a priori hypothesis, we observed reduced DMN-TPN segregation co-occurring with structural abnormalities in dorsolateral prefrontal cortex and anterior cingulate cortex, two important cognitive control regions. We also observed altered intranetwork connectivity in DMN, dorsal attention network, and visual network, with co-occurring distributed structural deficits. There was strong evidence of spatial correspondence across modalities: For all four components, the impact of the respective component on gray matter at a region strongly predicted the impact on functional connectivity at that region. Overall, our results demonstrate that ADHD involves multiple, cohesive modality spanning deficits, each one of which exhibits strong spatial overlap in the pattern of structural and functional alterations.
\end{abstract}

Key words: ADHD; default mode network; joint ICA; multimodal; resting state fMRI; structural MRI

\section{Introduction}

Attention-deficit/hyperactivity disorder (ADHD) is a serious and prevalent disorder characterized by age-inappropriate inattention, impulsivity, and hyperactivity. It has been studied in neuroimaging using multiple structural and functional imaging modalities. These investigations, however, have invariably been conducted independently, and the interrelationships between structural and functional abnormalities are thus poorly understood. In particular, it is not currently known whether structural and functional deficits are in any way linked, for example, by exhibiting patterns of spatial overlap or by being comanifestations of an underlying disease construct.

Recent years have seen the emergence of influential network models of ADHD (Sonuga-Barke and Castellanos, 2007; Castella-

\footnotetext{
Received July 30, 2014; revised 0ct. 10, 2014; accepted 0ct. 20, 2014.

Author contributions: D.K. and C.S. designed research; D.K. and C.S. performed research; D.K. and R.C.W. contributed unpublished reagents/analytic tools; D.K., M.A., and C.S. analyzed data; D.K. and C.S. wrote the paper.

C.S. was supported by National Institutes of Health Grant AA020297, Center for Computational Medicine Pilot Grant, and the John Templeton Foundation.

The authors declare no competing financial interests.

Correspondence should be addressed to Dr. Chandra Sripada, Department of Psychiatry, University of Michigan, Rachel Upjohn Building, Room 2743, 4250 Plymouth Road, Ann Arbor, MI 48109-2700.E-mail: sripada@umich.edu. DOI:10.1523/JNEUROSCI.3156-14.2014

Copyright $\odot 2014$ the authors $\quad 0270-6474 / 14 / 3416555-12 \$ 15.00 / 0$
}

nos and Proal, 2012) informed by the recognition that the human brain is organized into a number of large-scale intrinsic connectivity networks (ICNs) (Fox et al., 2005; Power et al., 2011). One important ICN, the default mode network (DMN), is implicated in internally directed mentation and mind wandering (Raichle et al., 2001; Buckner et al., 2008). It exhibits antagonistic relationships with ICNs that support externally directed attention ("task-positive networks" [TPNs]), including ventral attention network (VAN) and dorsal attention network (DAN) (Fox et al., 2005). According to current models, in individuals with $\mathrm{ADHD}$, there is reduced regulatory control of $\mathrm{DMN}$ by TPNs, leading to inappropriate intrusion of DMN during cognitively demanding tasks and lapses of attention (Weissman et al., 2006; Sonuga-Barke and Castellanos, 2007). Consistent with this model, altered patterns of internetwork functional connectivity have been demonstrated in ADHD in previous seed-based (Tian et al., 2006; Castellanos et al., 2008), graph theoretic (Di Martino et al., 2013; Ray et al., 2014), and whole-brain connectomic analyses (Sripada et al., 2014b, c). In addition, structural deficits have been identified in regulatory control regions, such as dorsal anterior cingulate cortex (dACC) and dorsolateral prefrontal cortex (dlPFC) (Seidman et al., 2005, 2006). These functional and structural findings have been identified in separate investigations, however, and it is not known whether these functional and struc- 
Table 1. Sample characteristics of the ADHD-200 dataset $^{a}$

\begin{tabular}{|c|c|c|c|c|c|c|c|c|}
\hline \multirow[b]{2}{*}{ Site } & \multicolumn{4}{|l|}{$\mathrm{HCS}$} & \multicolumn{4}{|c|}{ ADHD } \\
\hline & $n$ & Age & $\%$ male & 10 & $n$ & Age & $\%$ male & 10 \\
\hline \multicolumn{9}{|l|}{ Pre-exclusions } \\
\hline NYU & 93 & $12.1 \pm 3.1$ & 45.2 & $110.7 \pm 13.9$ & 116 & $11.3 \pm 2.7$ & 77.6 & $106.4 \pm 14.0$ \\
\hline Peking & 116 & $11.7 \pm 1.7$ & 61.2 & $118.1 \pm 13.3$ & 78 & $12.4 \pm 2.0$ & 91.0 & $105.4 \pm 13.2$ \\
\hline Pittsburgh & 89 & $15.1 \pm 2.9$ & 51.7 & $109.8 \pm 11.5$ & NA & & & \\
\hline OHSU & 41 & $8.9 \pm 1.2$ & 43.9 & $118.7 \pm 12.6$ & 37 & $8.8 \pm 1.0$ & 70.3 & $108.5 \pm 13.9$ \\
\hline Neurolmage & 22 & $17.3 \pm 2.6$ & 50.0 & 111.2 & 22 & $17.0 \pm 2.8$ & 81.8 & 111.2 \\
\hline Washington & 59 & $11.5 \pm 3.9$ & 52.5 & $116.0 \pm 14.1$ & NA & & & \\
\hline KKI & 61 & $10.3 \pm 1.3$ & 55.7 & $111.5 \pm 10.3$ & 22 & $10.2 \pm 1.6$ & 54.5 & $106.0 \pm 15.2$ \\
\hline Total & 481 & $12.2 \pm 3.3$ & 52.6 & $113.8 \pm 12.9$ & 275 & $11.6 \pm 3.0$ & 78.9 & $106.7 \pm 13.3$ \\
\hline \multicolumn{9}{|l|}{ Postexclusions } \\
\hline NYU & 49 & $12.7 \pm 2.9$ & 44.9 & $113.6 \pm 11.8$ & 52 & $11.7 \pm 3.1$ & 71.2 & $107.4 \pm 12.9$ \\
\hline Peking & 89 & $11.8 \pm 1.8$ & 58.4 & $118.1 \pm 11.8$ & 47 & $12.5 \pm 2.1$ & 91.5 & $105.8 \pm 12.5$ \\
\hline Pittsburgh & 54 & $15.7 \pm 2.8$ & 48.1 & $113.1 \pm 9.9$ & NA & & & \\
\hline OHSU & 19 & $9.2 \pm 1.5$ & 47.4 & $116.6 \pm 12.5$ & 15 & $9.2 \pm 1.3$ & 73.3 & $112.3 \pm 12.5$ \\
\hline Neurolmage & 15 & $17.0 \pm 2.4$ & 46.7 & 111.2 & 9 & $16.1 \pm 2.4$ & 88.9 & 111.2 \\
\hline Washington & 24 & $13.8 \pm 4.1$ & 45.8 & $114.9 \pm 11.2$ & NA & & & \\
\hline $\mathrm{KKI}$ & 38 & $10.5 \pm 1.3$ & 55.3 & $111.2 \pm 11.5$ & 10 & $11.1 \pm 1.7$ & 60.0 & $100.8 \pm 14.4$ \\
\hline Total & 288 & $12.8 \pm 3.2$ & 51.4 & $114.7 \pm 11.3$ & 133 & $11.90 .0 \pm 2.8$ & 78.9 & $107.2 \pm 12.5$ \\
\hline
\end{tabular}

${ }^{a}$ Sample characteristics are shown both before and after application of exclusion and quality control criteria. NYU, New York University; OHSU, Oregon Health and Science University; KKI, Kennedy Krieger Institute; NA, not applicable.

Table 2. Abbreviations for intrinsic connectivity networks used throughout text and figures

\begin{tabular}{ll}
\hline Abbreviation & Network name \\
\hline VN & Visual network \\
SMN & Somatomotor network \\
DAN & Dorsal attention network \\
VAN & Ventral attention network \\
LN & Limbic network \\
FPN & Frontoparietal network \\
DMN & Default mode network \\
\hline
\end{tabular}

tural deficits are interrelated and covary in severity across subjects.

More broadly, a number of theorists have looked across independent studies qualitatively and speculated that patterns of structural and functional alterations seen in ADHD represent a meaningful pattern; they seem to implicate functionally related neural circuits (Makris et al., 2007; Pironti et al., 2014) or exhibit patterns of spatial overlap (Shaw et al., 2007; Cortese et al., 2012). In the current study, we sought to investigate this hypothesis quantitatively using joint independent component analysis (ICA), a multivariate, multimodal method that identifies cohesive components that span modalities and covary across individuals. We submitted resting state whole-brain functional connectomes, gray matter volume maps, and white matter volume maps to joint ICA analysis. We hypothesized that functional abnormalities (i.e., altered DMN and TPN interrelations) and related structural abnormalities (gray and white matter abnormalities in cognitive control regions) in ADHD would load onto common components, indicating the presence of linked, covarying structural and functional deficits in ADHD. We also quantitatively tested the hypothesis that regions exhibiting gray matter alterations would also demonstrate changes in functional connectivity.

\section{Materials and Methods}

Participants. We used the ADHD-200 sample, which includes data from 756 participants (470 males and 286 females) with complete phenotypic information (diagnosis, age, gender, and handedness) who underwent MRI scanning at seven contributing sites. Of these, 481 participants were healthy controls (HCs) and 275 participants had received a DSM-IV-TR diagnosis of ADHD. Demographic characteristics of the sample are pro- vided in Table 1. Each site obtained informed consent, and all other procedures complied with institutional Human Investigation Review Boards. Fair et al. (2013) provide detailed reporting of phenotypics, assessment protocols, and scanning parameters.

Data acquisition. All participants were scanned on 3.0 Tesla scanners. Resting state scans used standard $\mathrm{T} 2{ }^{*}$-weighted echo-planar imaging. Structural scans used standard T1-weighted MPRAGE imaging. All data used are available at the Neuroimaging Informatics Tools and Resources Clearinghouse (http://fcon_1000.projects.nitrc.org/indi/adhd200).

Imaging sample selection and phenotypic imputation. Consistent with previous work (Sripada et al., 2014b, c), analyses were limited to participants with the following: (1) MPRAGE anatomical images with consistent near-full brain coverage (i.e., superior extent included the majority of frontal and parietal cortex and inferior extent included the temporal lobes) with successful registration; (2) complete phenotypic information for main phenotypic variables (diagnosis, age, gender, and handedness), although imputation was allowed for missing IQ data (see below); (3) full IQ within 2 SDs of the overall sample mean; (4) mean framewise displacement within 2 SDs of the sample mean; and (5) no more than $60 \%$ of functional frames removed after application of framewise censoring for motion ('motion scrubbing'; see Connectome generation).

After applying these sample selection criteria, we analyzed data from 421 individuals $(\mathrm{HC}=288$; $\mathrm{ADHD}=133$ ) from seven sites spanning an age range from 7 to 22 years. Demographic characteristics of the preexclusion and postexclusion sample are shown in Table 1. Of note, for participants lacking an F4 or F2 IQ score, full IQ was estimated by averaging the participant's performance and verbal IQ scores. For participants without any IQ information (which included all participants from the NeuroImage site), the mean IQ across other participants was imputed.

Preprocessing. Preprocessing steps were performed using statistical parametric mapping (SPM8; www.fil.ion.ucl.ac.uk/spm). Scans were reconstructed, slice-time corrected, realigned to the tenth frame, and coregistered with the high-resolution T1-weighted image. Using the voxel-based morphometry toolbox (VBM8; http://dbm.neuro.uni-jena.de/vbm), the high-resolution T1-weighted image was bias-corrected, segmented into tissue types, registered to MNI space, and then normalized using Diffeomorphic Anatomical Registration Through Exponentiated Lie Algebra (Ashburner, 2007). The generated maps were modulated for nonlinear effects (which renders resultant values as relative volumes controlled for different brain sizes) and retained for later VBM analysis. The resulting deformation fields were then applied to the functional images. Smoothing of functional data and gray/white matter maps was performed with an $8 \mathrm{~mm}^{3}$ kernel. 
Table 3. Abbreviations for subregions used in figures, arranged by ICN

\begin{tabular}{cl}
\hline Abbreviation & Region name \\
\hline Visual network & \\
FUS & Fusiform gyrus \\
LING & Lingual gyrus \\
CNS & Cuneus \\
SOC & Superior occipital cortex \\
MOC & Middle occipital cortex \\
IOC & Inferior occipital cortex \\
Somatomotor network & \\
SMA & Supplementary motor area \\
PRE & Precentral gyrus \\
POST & Postcentral gyrus \\
STG & Superior temporal gyrus \\
Dorsal attention network & \\
SF & Superior frontal \\
PRE & Precentral gyrus \\
MTG & Middle temporal gyrus \\
ITG & Inferior temporal gyrus \\
SP & Superior parietal \\
IPL & Inferior parietal lobule \\
PCN & Precuneus \\
OCC ${ }^{a}$ & Occipital cortex \\
Ventral attention network & Middle lateral prefrontal cortex \\
mIPFC & Supplementary motor area \\
SMA & Anterior insula \\
aINS & Precentral gyrus \\
PRE ${ }^{a}$ & Supramarginal gyrus \\
SMG & Anterior precuneus \\
aPCN & \\
Frontoparietal network & Posterior cingulate cortex \\
SIPFC & Angular gyrus \\
dIPFC & Superior lateral prefrontal cortex \\
vIPFc & Dorsolateral prefrontal cortex \\
OFC & Ventrolateral prefrontal cortex \\
mINS & Orbital frontal cortex \\
SFG & Medial insula \\
MCC & Superior frontal gyrus \\
ITG & Mid cingulate cortex \\
LPL & Inferior temporal gyrus \\
pPCN & Lateral parietal lobule \\
Default mode network & Posterior precuneus \\
dmPFC & \\
vmPFC & Dorsomedial prefrontal cortex \\
OIFG & Ventromedial prefrontal cortex \\
LTL & Orbital inferior frontal gyrus \\
MTL & Lateral temporal lobe \\
ANC & MNG \\
\hline
\end{tabular}

${ }^{a}$ Regions were not depicted in circle graphs as they did not participate in sufficient connections (as discussed in Materials and Methods).

Connectome generation. Whole-brain resting state functional connectomes were generated using methods similar to our previous work (Sripada et al., 2013, 2014a, b, c; Watanabe et al., 2014). In brief, after linear detrending, regression was performed to remove nuisance effects in each voxel's time-series. Regressors included six motion terms generated from the realignment step as well as their first derivatives. The top five principal components of the BOLD time-series were extracted from CSF and white matter masks and included as regressors, a method that has been demonstrated to effectively remove signals arising from the cardiac and respiratory cycle (Behzadi et al., 2007). The time-series for each voxel was next bandpass filtered in the $0.01-0.10 \mathrm{~Hz}$ range. Next, motion scrubbing (removal of individual frames with excessive head motion from the time-series) was performed, with framewise displacement threshold for excessive motion set at $0.2 \mathrm{~mm}$ (Fair et al., 2013). One frame before and two frames after the target frame were also removed to account for temporal blurring (Power et al., 2011). Subjects with $>60 \%$ of their frames
Table 4. Clusters in gray and white matter: Component $1^{a}$

\begin{tabular}{|c|c|c|c|c|c|c|c|}
\hline \multirow[b]{2}{*}{ Modality } & \multirow[b]{2}{*}{ Direction } & \multirow{2}{*}{$\begin{array}{l}\text { Volume } \\
\left(\mathrm{mm}^{3}\right)\end{array}$} & \multirow{2}{*}{ Zscore } & \multicolumn{3}{|c|}{ MNI coordinates } & \multirow[b]{2}{*}{ Region } \\
\hline & & & & $x$ & $\gamma$ & Z & \\
\hline \multirow[t]{15}{*}{ Gray matter } & \multirow[t]{5}{*}{ Positive } & 2670 & 3.04 & 45 & -64.5 & 31.5 & ANG \\
\hline & & 1367 & 2.93 & -19.5 & -99 & -12 & IOG \\
\hline & & 1286 & 2.88 & 52.5 & 22.5 & 12 & IFG \\
\hline & & 1772 & 2.83 & -43.5 & -58.5 & 43.5 & ANG \\
\hline & & 4317 & 2.80 & 64.5 & -19.5 & 1.5 & STG, SMG \\
\hline & \multirow[t]{10}{*}{ Negative } & 27,560 & -6.10 & -57 & -19.5 & -25.5 & $\begin{array}{l}\text { TP, ITG, MTG, FG, } \\
\text { PHG }\end{array}$ \\
\hline & & 15,086 & -5.81 & 55.5 & -10.5 & -31.5 & TP, ITG, FG, PHG \\
\hline & & 19,538 & -4.99 & -24 & 28.5 & 36 & MFG, IFG, SFG \\
\hline & & 12,639 & -4.84 & -6 & 34.5 & 18 & $\mathrm{ACC}$ \\
\hline & & 1141 & -4.35 & 30 & -66 & 33 & MOG \\
\hline & & 5802 & -3.61 & 25.5 & 57 & -4.5 & SFG, MFG \\
\hline & & 1900 & -2.72 & -37.5 & -54 & -54 & Cerebellum \\
\hline & & 1269 & -2.55 & 22.5 & -78 & -48 & Cerebellum \\
\hline & & 1097 & -2.51 & 34.5 & -69 & -25.5 & Cerebellum \\
\hline & & 1158 & -2.48 & -34.5 & -76.5 & -27 & Cerebellum \\
\hline \multirow[t]{28}{*}{ White matter } & \multirow[t]{14}{*}{ Positive } & 7229 & 5.98 & 54 & -45 & -16.5 & SLF, ILF \\
\hline & & 19,778 & 5.97 & -49.5 & -45 & -7.5 & $\begin{array}{l}\text { SLF, ILF, CT, } \\
\text { cingulum }\end{array}$ \\
\hline & & 7034 & 5.30 & -33 & -73.5 & -9 & $\begin{array}{l}\text { ILF, IFOF, forceps } \\
\text { major, cingulum }\end{array}$ \\
\hline & & 9757 & 5.23 & 30 & -57 & 39 & $\begin{array}{l}\text { SLF, cingulum, } \\
\text { ATR, CT }\end{array}$ \\
\hline & & 3230 & 4.60 & -30 & 45 & -7.5 & IFOF, ATR \\
\hline & & 1839 & 3.98 & 39 & 45 & -9 & IFOF \\
\hline & & 1458 & 3.69 & -52.5 & -18 & 24 & SLF \\
\hline & & 2224 & 3.65 & 60 & -33 & 12 & ILF \\
\hline & & 1100 & 3.55 & 46.5 & 15 & 7.5 & SLF \\
\hline & & 1161 & 3.45 & -55.5 & -15 & -3 & SLF \\
\hline & & 1826 & 3.22 & 30.75 & -81.75 & 11.25 & $\begin{array}{l}\text { IFOF, forceps } \\
\text { major }\end{array}$ \\
\hline & & 1235 & 3.19 & 12 & -54 & -43.5 & CT \\
\hline & & 1694 & 3.11 & -19.5 & 16.5 & -16.5 & UF \\
\hline & & 3119 & 3.00 & -27 & -60 & -46.5 & ATR, CT \\
\hline & \multirow[t]{14}{*}{ Negative } & 2730 & -5.06 & 1.5 & -43.5 & -63 & $\mathrm{CT}$ \\
\hline & & 1286 & -4.92 & -30 & -46.5 & 51 & SLF \\
\hline & & 1833 & -4.75 & -19.5 & -69 & 33 & ILF \\
\hline & & 5387 & -4.67 & 1.5 & -37.5 & 13.5 & Forceps major \\
\hline & & 1242 & -4.63 & 37.5 & 10.5 & 42 & SLF \\
\hline & & 3659 & -4.62 & -45 & 13.5 & 15 & SLF, IFOF \\
\hline & & 1171 & -4.25 & -7.5 & -82.5 & 28.5 & Forceps major \\
\hline & & 3891 & -3.97 & -18 & 25.5 & 37.5 & $\begin{array}{l}\text { ATR, cingulum, } \\
\text { forceps minor }\end{array}$ \\
\hline & & 2319 & -3.66 & -34.5 & -25.5 & -19.5 & ILF, cingulum \\
\hline & & 1094 & -3.21 & 22.5 & 54 & 15 & ATR \\
\hline & & 4674 & -3.18 & 4.5 & 6 & 22.5 & SLF, forceps minor \\
\hline & & 3929 & -3.08 & 0 & -25.5 & -36 & $\mathrm{CT}$ \\
\hline & & 1796 & -3.03 & -36 & 7.5 & -36 & ILF, SLF \\
\hline & & 1326 & -2.92 & 27 & 6 & -1.5 & IFOF, UF \\
\hline
\end{tabular}

${ }^{a}$ Maps were thresholded at $z>2$, and contiguous clusters encompassing volumes $>1012.5 \mathrm{~mm}^{3}$ (300 voxels) are reported. Z scores and coordinates correspond to the peak voxel within each cluster. Gray matter regions are labeled using the AAL atlas, whereas white matter regions are labeled according to the JHU atlas. Abbreviations are defined in Table 8.

removed by scrubbing were excluded from further analysis, a threshold justified by simulations conducted by other groups (Fair et al., 2013) as well as by our group.

We then placed 4.24 (i.e., $3 \sqrt{ } 2$ ) $\mathrm{mm}$ radius regions of interest (ROIs) (encompassing $193 \times 3 \times 3 \mathrm{~mm}$ voxels) in a regular grid spaced at 12 $\mathrm{mm}$ intervals throughout the brain resulting in 1166 psuedo-spherical ROIs (for a substantial discussion of grid-based parcellation schemes, see Watanabe et al., 2014). Spatially averaged time-series were then extracted from each ROI. Next, Pearson product-moment correlation coefficients were calculated pairwise between time courses for each of the 1166 ROIs, followed by Fisher's r-to- $z$ transformation to introduce normality. Based on the network map of Yeo et al. (2011), each connection was then 
Table 5. Clusters in gray and white matter: Component $4^{a}$

\begin{tabular}{|c|c|c|c|c|c|c|c|}
\hline \multirow[b]{2}{*}{ Modality } & \multirow[b]{2}{*}{ Direction } & \multirow{2}{*}{$\begin{array}{l}\text { Volume } \\
\left(\mathrm{mm}^{3}\right)\end{array}$} & \multirow[b]{2}{*}{ Zscore } & \multicolumn{3}{|c|}{ MNI coordinates } & \multirow[b]{2}{*}{ Region } \\
\hline & & & & $x$ & Y & Z & \\
\hline \multirow[t]{13}{*}{ Gray matter } & Positive & 6524 & 6.27 & 3 & -16.5 & 6 & Thalamus \\
\hline & & 8319 & 4.83 & 43.5 & -27 & 18 & Insula \\
\hline & & 11,654 & 4.62 & -30 & -48 & -54 & Cerebellum \\
\hline & & 8718 & 4.28 & 22.5 & 10.5 & -6 & Putamen, caudate \\
\hline & & 15,289 & 3.91 & 28.5 & -46.5 & -52.5 & Cerebellum \\
\hline & & 6136 & 3.28 & -40.5 & -30 & 15 & Insula \\
\hline & & 1046 & 3.07 & 43.5 & -66 & 6 & MTG \\
\hline & & 1583 & 2.93 & 30 & -43.5 & -10.5 & FG \\
\hline & Negative & 30,740 & -7.39 & 19.5 & -70.5 & 7.5 & $\begin{array}{l}\text { Cuneus, SOG, MOG, } \\
\text { calcarine }\end{array}$ \\
\hline & & 3534 & -3.92 & -36 & 19.5 & 40.5 & MFG \\
\hline & & 1654 & -3.56 & 21 & -10.5 & 60 & SFG, SMA \\
\hline & & 1421 & -3.22 & -43.5 & -55.5 & 22.5 & MTG \\
\hline & & 1110 & -2.82 & -52.5 & -27 & 34.5 & SMG \\
\hline \multirow[t]{9}{*}{ White matter } & Positive & 4064 & 4.97 & 0 & -37.5 & 13.5 & Forceps major \\
\hline & & 15,248 & 4.81 & 0 & -42 & -58.5 & СТ \\
\hline & & 8174 & 3.36 & 0 & 10.5 & 19.5 & $\begin{array}{l}\text { SLF, cingulum, forceps } \\
\text { minor }\end{array}$ \\
\hline & & 1229 & 3.34 & 48 & -39 & 19.5 & SLF \\
\hline & & 1620 & 3.24 & 16.5 & -64.5 & 42.75 & IFOF \\
\hline & & 4269 & 3.24 & -42 & 21 & 10.5 & IFOF, SLF \\
\hline & & 4563 & 3.18 & 18 & 48 & 15 & $\begin{array}{l}\text { Forceps minor, ATR, } \\
\text { cingulum }\end{array}$ \\
\hline & & 1053 & 3.17 & 46.5 & -24 & 27 & SLF \\
\hline & Negative & 61,968 & -7.75 & -13.5 & -90 & 16.5 & Forceps major, IFOF, ILF \\
\hline
\end{tabular}

$\overline{{ }^{a} \text { Maps were thresholded at } z>2 \text {, and contiguous clusters encompassing volumes }>1012.5 \mathrm{~mm}^{3} \text { (300 voxels) are }}$ reported. Z scores and coordinates correspond to the peak voxel within each cluster. Gray matter regions are labeled using the AAL atlas, whereas white matter regions are labeled according to the JHU atlas. Abbreviations are defined in Table 8.

assigned to a network pair based on the large-scale ICN in which it originated and terminated. A total of 907 of these ROIs fell within $5 \mathrm{~mm}$ from the cortical parcellation of the brain, and this subset was used for display and spatial correspondence analysis (described below).

Second-level cleansing. Because participants in this sample represent data collected at a number of contributing sites, second-level cleansing was performed to remove site-related variation as well as nuisance variation contributed by other factors. More specifically, we performed a per-feature regression to remove nuisance effects of age, age squared, mean motion (framewise displacement), mean motion squared, IQ, gender, and scanning site (dummy coded into a series of dichotomous predictors). We removed all variance not captured in either diagnosis or residuals.

Joint ICA. Joint ICA, as introduced by Calhoun et al. (2006a), was performed. The steps proceeded as follows.

Modality vectorization. Features (voxels and correlation coefficients) were combined into a single per-subject feature vector. Past work provides schematic representation and mathematical motivation for this approach (Calhoun et al., 2006a, 2009; Sui et al., 2011).

Feature normalization and dimensionality reduction. Features from each modality were normalized to have mean sum of squares set at unity. To prevent values close to zero from having significant effects, the approach of Calhoun et al. (2006a) was used: Alternating white and gray matter features were multiplied by -1 for analysis and subsequently reversed at the time of component inspection. Initial data reduction was performed using PCA (reducing subjects). In addition, a dewhitening matrix, capable of casting data from the reduced space back to the full space, was retained. Model order was set at 15, similar to prior joint ICA studies (Calhoun et al., 2006a, b), and consistent with findings that lower model orders (i.e., 10-20 components) are most effective for uncovering large-scale networks (Abou-Elseoud et al., 2010; Ray et al., 2013).

ICA. The reduced data were then submitted to an ICA decomposition using the FastICA algorithm (Hyvärinen, 1999), which returned source maps and a mixing matrix. The mixing matrix was dewhitened using the matrix from the PCA data reduction stage, yielding subject-specific mixing coefficients for each component. ICASSO (Himberg et al., 2004), run
Table 6. Clusters in gray and white matter: Component $9^{a}$

\begin{tabular}{|c|c|c|c|c|c|c|c|}
\hline \multirow[b]{2}{*}{ Modality } & \multirow[b]{2}{*}{ Direction } & \multirow{2}{*}{$\begin{array}{l}\text { Volume } \\
\left(\mathrm{mm}^{3}\right)\end{array}$} & \multirow[b]{2}{*}{ Zscore } & \multicolumn{3}{|c|}{ MNI coordinates } & \multirow[b]{2}{*}{ Region } \\
\hline & & & & $x$ & $Y$ & $Z$ & \\
\hline \multirow[t]{26}{*}{ Gray matter } & \multirow[t]{15}{*}{ Positive } & 17,854 & 5.87 & 58.5 & -25.5 & -22.5 & ITG, MTG \\
\hline & & 2680 & 5.63 & 27 & -63 & 39 & SOG, cuneus \\
\hline & & 5576 & 4.98 & 19.5 & -82.5 & -34.5 & Cerebellum \\
\hline & & 4239 & 4.51 & -43.5 & -55.5 & 22.5 & MTG, ANG \\
\hline & & 4229 & 4.29 & 31.5 & -12 & -36 & FG \\
\hline & & 2140 & 4.26 & -30 & -9 & -37.5 & FG \\
\hline & & 1029 & 4.20 & 16.5 & -15 & 67.5 & SFG \\
\hline & & 1411 & 4.07 & 9 & 46.5 & -25.5 & GR \\
\hline & & 1623 & 3.93 & -55.5 & -22.5 & 31.5 & POST, SMG, IPG \\
\hline & & 2130 & 3.91 & 58.5 & -43.5 & 24 & SMG \\
\hline & & 9325 & 3.89 & -18 & -84 & -37.5 & Cerebellum \\
\hline & & 1890 & 3.73 & 41.25 & 12.75 & 27 & IFG \\
\hline & & 1087 & 3.72 & 55.5 & -19.5 & 33 & POST \\
\hline & & 3011 & 3.54 & 37.5 & -61.5 & -55.5 & Cerebellum \\
\hline & & 2879 & 2.86 & -12 & 28.5 & -24 & SFG, IFG, TP \\
\hline & \multirow[t]{11}{*}{ Negative } & 2838 & -6.17 & 33 & -49.5 & 40.5 & IPG \\
\hline & & 1742 & -4.37 & 37.5 & 25.5 & 36 & MFG \\
\hline & & 9464 & -4.10 & 0.75 & -54.75 & -46.5 & Cerebellum \\
\hline & & 9015 & -3.66 & 16.5 & -61.5 & 52.5 & SPG, precuneus \\
\hline & & 1863 & -3.61 & -15 & -90 & 27 & SOG, cuneus \\
\hline & & 1357 & -3.53 & 1.5 & -87 & -18 & Cerebellum \\
\hline & & 3902 & -3.37 & 18 & -73.5 & 9 & $\begin{array}{r}\mathrm{LG} \text {, calcarine, } \\
\text { precuneus }\end{array}$ \\
\hline & & 1242 & -3.10 & 7.5 & 22.5 & 43.5 & SFG \\
\hline & & 1718 & -3.07 & -24 & -64.5 & 4.5 & Calcarine \\
\hline & & 2322 & -2.81 & -55.5 & -34.5 & 12 & STG, SMG \\
\hline & & 1407 & -2.55 & 34.5 & -3 & -6 & Putamen, insula \\
\hline \multirow[t]{24}{*}{ White matter } & \multirow[t]{13}{*}{ Positive } & 6770 & 6.28 & 1.5 & -36 & 13.5 & Forceps major, SLF \\
\hline & & 12,629 & 5.96 & 42 & -51 & 39 & SLF, IFOF \\
\hline & & 7064 & 4.67 & 31.5 & 3 & 48 & SLF, cingulum \\
\hline & & 4458 & 4.60 & -31.5 & 0 & 45 & SLF, cingulum \\
\hline & & 2602 & 4.54 & -48 & -49.5 & -9 & SLF \\
\hline & & 5302 & 4.54 & 54 & -43.5 & -3 & SLF, ILF \\
\hline & & 3618 & 4.20 & -40.5 & -39 & 39 & SLF \\
\hline & & 1073 & 3.89 & -31.5 & 28.5 & 30 & ATR, SLF \\
\hline & & 2221 & 3.58 & 33 & -1.5 & -13.5 & UF \\
\hline & & 1650 & 3.40 & -15 & 12 & 54 & SLF \\
\hline & & 2865 & 3.25 & 31.5 & 37.5 & 25.5 & ATR, IFOF \\
\hline & & 1202 & 3.19 & 13.5 & -21 & 60 & СТ \\
\hline & & 2241 & 3.07 & -37.5 & 42 & -9 & IFOF, ATR \\
\hline & \multirow[t]{11}{*}{ Negative } & 9035 & -5.59 & 16.5 & -91.5 & 13.5 & $\begin{array}{l}\text { Forceps major, } \\
\text { IFOF }\end{array}$ \\
\hline & & 10,986 & -5.07 & -28.5 & -55.5 & -51 & CT, ATR \\
\hline & & 13,939 & -4.99 & -10.5 & -87 & -9 & $\begin{array}{l}\text { ILF, forceps major, } \\
\text { IFOF, ATR }\end{array}$ \\
\hline & & 1664 & -4.64 & 54 & -24 & -24 & SLF \\
\hline & & 1357 & -4.41 & -27 & 0 & 3 & SLF \\
\hline & & 5403 & -4.37 & 31.5 & -67.5 & -46.5 & CT \\
\hline & & 1458 & -3.90 & 46.5 & -64.5 & -9 & ILF, SLF \\
\hline & & 1063 & -3.85 & 40.5 & 9 & -37.5 & ILF \\
\hline & & 1357 & -3.61 & -49.5 & -18 & -30 & SLF, ILF \\
\hline & & 2656 & -3.60 & 45 & 18 & 9 & SLF \\
\hline & & 2383 & -3.46 & 46.5 & -24 & 54 & ILF, SLF \\
\hline
\end{tabular}

${ }^{a}$ Maps were thresholded at $z>2$, and contiguous clusters encompassing volumes $>1012.5 \mathrm{~mm}^{3}$ (300 voxels) are reported. Zscores and coordinates correspond to the peak voxel within each cluster. Gray matter regions are labeled using the AAL atlas, whereas white matter regions are labeled according to the JHU atlas. Abbreviations are defined in Table 8.

1000 times, indicated that all components were stable $\left(I_{\mathrm{q}}\right.$ ranged from 0.8370 to 0.9990 ) (Khadka et al., 2013).

To identify which components had significantly different expression as a function of ADHD diagnosis, we conducted a multiple regression with component expression scores as outcome and diagnosis (ADHD vs $\mathrm{HC}$ ) as predictor. The other covariates from the "Second Level Cleansing" step above were included as nuisance covariates. Results for diagnosis were false discovery rate corrected for multiple comparisons arising from testing across multiple components according to the method of 
Table 7. Clusters in gray and white matter: Component $12^{a}$

\begin{tabular}{|c|c|c|c|c|c|c|c|}
\hline \multirow[b]{2}{*}{ Modality } & \multirow{2}{*}{ Direction } & \multirow{2}{*}{$\begin{array}{l}\text { Volume } \\
\left(\mathrm{mm}^{3}\right)\end{array}$} & \multirow{2}{*}{ Zscore } & \multicolumn{3}{|c|}{ MNI coordinates } & \multirow[b]{2}{*}{ Region } \\
\hline & & & & $x$ & $Y$ & $Z$ & \\
\hline \multirow[t]{18}{*}{ Gray matter } & Positive & 5636 & 6.00 & 30 & -66 & 33 & MOG, SOG, SPG, cuneus \\
\hline & & 20257 & 5.40 & -21 & -12 & 60 & SFG, PRE, SMA \\
\hline & & 7536 & 5.34 & -31.5 & -40.5 & 54 & POST, SPG \\
\hline & & 1566 & 4.47 & -28.5 & -75 & 25.5 & MOG \\
\hline & & 2984 & 4.03 & -0.75 & -18 & 6 & Thalamus \\
\hline & & 1181 & 4.01 & 28.5 & -25.5 & 52.5 & PRE \\
\hline & & 3075 & 3.47 & 40.5 & 4.5 & 36 & MFG \\
\hline & & 1377 & 3.20 & 57 & -43.5 & 30 & SMG \\
\hline & & 2825 & 3.12 & 15 & -82.5 & -30 & Cerebellum \\
\hline & & 1043 & 2.77 & 7.5 & -73.5 & 12 & Calcarine \\
\hline & Negative & 1394 & -5.33 & 51 & -22.5 & 37.5 & POST \\
\hline & & 22032 & -5.15 & -57 & -51 & -10.5 & MTG, ITG, ANG, FG, MOG \\
\hline & & 12258 & -4.85 & 9 & -45 & 34.5 & $\mathrm{MCC}$ \\
\hline & & 3102 & -4.61 & 42 & -60 & 28.5 & ANG \\
\hline & & 7219 & -4.11 & 58.5 & -37.5 & -15 & ITG, MTG \\
\hline & & 10841 & -3.81 & -7.5 & 45 & 4.5 & $A C C, G R, M F G$, SFG \\
\hline & & 2687 & -3.52 & -31.5 & -30 & -19.5 & FG \\
\hline & & 1799 & -2.99 & -46.5 & -55.5 & -42 & Cerebellum \\
\hline \multirow{18}{*}{ White matter } & Positive & 23480 & 6.74 & -30 & -46.5 & 51 & SLF, CT, cingulum \\
\hline & & 3628 & 5.43 & 27 & -87 & 15 & ILF, forceps major \\
\hline & & 15491 & 4.88 & 40.5 & 1.5 & 45 & SLF, CT, ATR \\
\hline & & 1586 & 4.83 & 28.5 & -58.5 & 48 & SLF \\
\hline & & 1340 & 3.90 & 48 & 15 & 10.5 & SLF \\
\hline & & 1482 & 3.86 & 36 & -15 & -28.5 & Cingulum \\
\hline & & 1262 & 2.93 & -15 & -88.5 & 18 & Forceps major \\
\hline & & 1114 & 2.74 & 33 & 3 & -36 & Cingulum \\
\hline & Negative & 8235 & -6.60 & 48 & -36 & 39 & SLF \\
\hline & & 9393 & -6.33 & -39 & -60 & 34.5 & SLF, cingulum, ATR \\
\hline & & 13834 & -6.31 & -51 & -57 & -7.5 & ILF, SLF, IFOF \\
\hline & & 4664 & -5.91 & 51 & -51 & -10.5 & ILF, SLF \\
\hline & & 4509 & -5.09 & -48 & -37.5 & 34.5 & SLF \\
\hline & & 4887 & -4.60 & 10.5 & -94.5 & 4.5 & Forceps major \\
\hline & & 6362 & -4.58 & 13.5 & -60 & 57 & Cingulum, ATR, IFOF \\
\hline & & 2744 & -3.96 & -15 & 54 & 3 & Forceps minor, UF \\
\hline & & 2892 & -3.21 & 30 & 43.5 & 6 & ATR, IFOF \\
\hline & & 1087 & -2.75 & -24 & -76.5 & -33 & $\mathrm{CT}$ \\
\hline
\end{tabular}

$\overline{{ }^{a} \text { Maps were thresholded at } z>2 \text {, and contiguous clusters encompassing volumes }>1012.5 \mathrm{~mm}^{3} \text { (300 voxels) are }}$ reported. Zscores and coordinates correspond to the peak voxel within each cluster. Gray matter regions are labeled using the AAL atlas, whereas white matter regions are labeled according to the JHU atlas. Abbreviations are defined in Table 8.

Benjamini and Hochberg (1995). Although the sign of coefficient loadings is arbitrary and can vary when rerunning ICA, we have adopted the convention of describing and displaying components in terms of increased expression in ADHD. To assist with visualization, each statistically significant component's corresponding source map was separated into constituent connectivity, gray matter, and white matter maps, $z$-scored by subtracting mean and dividing by SD, thresholded, and displayed. The 3D structural maps are thresholded at $|z|>2$ (see subsections $\mathrm{A}$ and $\mathrm{B}$ of all figures).

To visualize the much larger connectomes, we first thresholded the source maps at $|z|>3$ such that all connections were nonsignificant, positive, or negative. Next, we restructured the correlation matrix such that nodes were sorted by network affiliation, overlaid lines indicating divisions between networks, and rendered the upper triangular portion of this matrix for the seven cortical ICNs (see subsection $\mathrm{C}$ of all figures).

Comparing connectivity with baseline. Prior theory has proposed that there is decreased segregation between DMN and two important TPNs (DAN and VAN) in ADHD (Sonuga-Barke and Castellanos, 2007; Kelly et al., 2008; Castellanos and Proal, 2012; see Introduction). To elaborate on this claim, we performed an additional post hoc analysis on Component 1 (which in our results exhibited aberrant DMN-TPN interrelationships). For DMN-DAN and DMN-VAN specifically, we examined the suprathreshold connections from Component 1 in HCs alone in terms of baseline status (i.e., anticorrelated vs positively correlated). We then calculated the proportion of these connections that demonstrated decreased segregation (i.e., these connections were anticorrelated in HCs
Table 8. Abbreviations used in cluster tables (Tables 4-7)

\begin{tabular}{ll}
\hline Abbreviation & Term \\
\hline ACC & Anterior cingulate cortex \\
ANG & Angular gyrus \\
ATR & Anterior thalamic radiation \\
CT & Cerebrospinal tract \\
FG & Fusiform gyrus \\
GR & Gyrus rectus \\
IFG & Inferior frontal gyrus \\
IFOF & Inferior fronto-occipital fasciculus \\
ILF & Inferior longitudinal fasciculus \\
IOG & Inferior occipital gyrus \\
IPG & Inferior parietal gyrus \\
ITG & Inferior temporal gyrus \\
LG & Lingual gyrus \\
MCC & Mid cingulate cortex \\
MFG & Middle frontal gyrus \\
MOG & Middle occipital gyrus \\
MTG & Middle temporal gyrus \\
PHG & Parahippocampal gyrus \\
POST & Postcentral gyrus \\
PRE & Precentral gyrus \\
SFG & Superior frontal gyrus \\
SLF & Superior longitudinal fasciculus \\
SMA & Supplementary motor area \\
SMG & Supramarginal gyrus \\
SOG & Superior occipital gyrus \\
SPG & Superior parietal gyrus \\
STG & Superior temporal gyrus \\
TP & Temporal pole \\
UF & Uncinate fasciculus \\
\hline
\end{tabular}

and were positive in our component, indicating attenuations of these anticorrelations).

Generating circle graphs. To more closely examine the relationships between pairs of networks, we generated circle graphs that display the patterns of alterations between individual subregions within networks (see subsection D of all figures). In brief, the width of the arcs linking a pair of subregions represents the number of abnormal connections between those subregions, relative to the overall population of abnormal internetwork connections. For example, if most of the abnormal connections between VAN and DMN link two specific subregions (e.g., anterior insula and posterior cingulate cortex), then the width of the arc connecting these two subregions will be correspondingly larger. A more thorough reporting of the procedure for circle graph generation follows.

To generate these circle graphs, we first divided each ICN into a number of distinct subregions based on contiguous clusters, MNI coordinates, and anatomical parcellations. We then connected these subregions with arcs. In computing the width of an arc connecting two subregions, we did the following: Let $P$ be the size of the population of connections surviving thresholding for a given pair of networks (e.g., DMN-DAN, VAN-VAN). Let $L$ be the number of connections within this population that links a pair of subregions. The width of the arc connecting this pair of subregions was then set to be proportional to $L / P$. Of note, to enhance the readability of the circle graphs, arcs that represent $<1 \%$ of the internetwork connections were omitted. In addition, any subregions where both left and right sides participated in $<1 \%$ of per-graph connections for all visualizations were omitted from graphs.

Scale measures of symptom severity. In addition, we were interested in how measures of ADHD symptom severity would differentially predict component expression. Inattention and hyperactivity/impulsivity scores were available for $180(\mathrm{ADHD}=77)$ of the 421 participants in the present analysis [measured using either The Conners' Parent Rating ScaleRevised, Long Version (Conners et al., 1998) or the Conners' Rating Scale, 3rd Edition (Kao and Thomas, 2010); other participants had either different measures of ADHD severity or none at all]. To evaluate their predictive value, we fit a linear model, including both inattention and 
hyperactivity/impulsivity scores as predictors in addition to the nuisance covariates described above.

Assessing spatial correspondence of gray matter and functional connectivity effects. We hypothesized that cortical regions experiencing substantial gray matter modulation as a function of component expression would display correspondingly aberrant connectivity. We investigated this hypothesis by calculating component-specific per-ROI impact scores for gray matter and functional connectivity, respectively, at the 907 cortical ROIs. The method, repeated independently for each component of interest, went as follows. We took the absolute value at all voxels as our hypothesis was about gray matter effects regardless of sign. Next, we calculated the average gray matter $z$-score within each ROI. This yielded a perROI gray matter impact score that reflects the degree to which gray matter contained within that ROI was affected in a given component. The process to obtain per-ROI functional connectivity impact scores was similar. First, we took the absolute value of $z$-scores from the connectivity map as our hypothesis was about connectivity effects regardless of sign. Next, for each ROI, we averaged the $z$-scores for all the connections in which this ROI participated. This per-ROI connectivity impact score reflects the degree to which the connectivity patterns of that ROI are affected in a component.

We then calculated correlation coefficients separately for each component between the respective gray matter impact score maps and connectivity impact score maps. Because ROIs may exhibit some spatial dependence, statistical significance of these correlations was assessed as follows. For each component, we estimated the smoothness of the gray matter impact score map and connectivity impact score map, respectively, using Analysis of Functional NeuroImages's (http://afni.nimh.nih.gov/afni/) 3dFWHMx utility. These smoothness estimates served as inputs to Analysis of Functional NeuroImages's 3dClustSim utility as we generated 10,000 new pairs of random maps. These random maps represent realizations of the null hypothesis of no intermodal correlation but have comparable spatial dependence to our observed components. Similar to the process in our real data, we calculated the intermodal correlation across ROIs for each of these 10,000 pairs. This process yielded 10,000 correlation coefficients that served as an estimate of the null distribution of no intermodal correlation given our spatial smoothness. The correlation coefficient observed in the real data was located in this distribution to yield a one-sided $p$ value. In cases where the observed value was greater than all values in the null distribution, the $p$ value was reported as $<0.0001$, the smallest $p$ value that can be obtained from 10,000 realizations of the null distribution.

\section{Results}

Our multiple regression analysis identified four components that were significantly modulated as a function of ADHD diagnosis ( $p<0.05$, false discovery rate-corrected). The identities of these components were $1,4,9$, and 12 , respectively (corresponding test statistics and uncorrected $p$ values were $t_{(407)}=3.03,2.61,2.80$, and $3.19, p=0.0026,0.0094,0.0055$, and 0.0015 , respectively; of
C
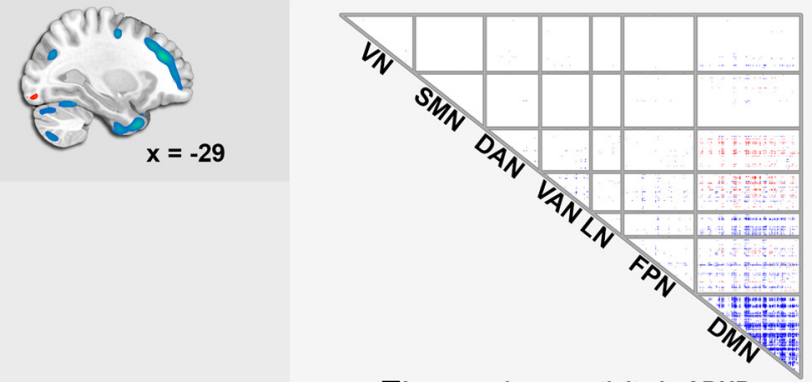

$\square$ Increased connectivity in ADHD Decreased connectivity in ADHD Z score
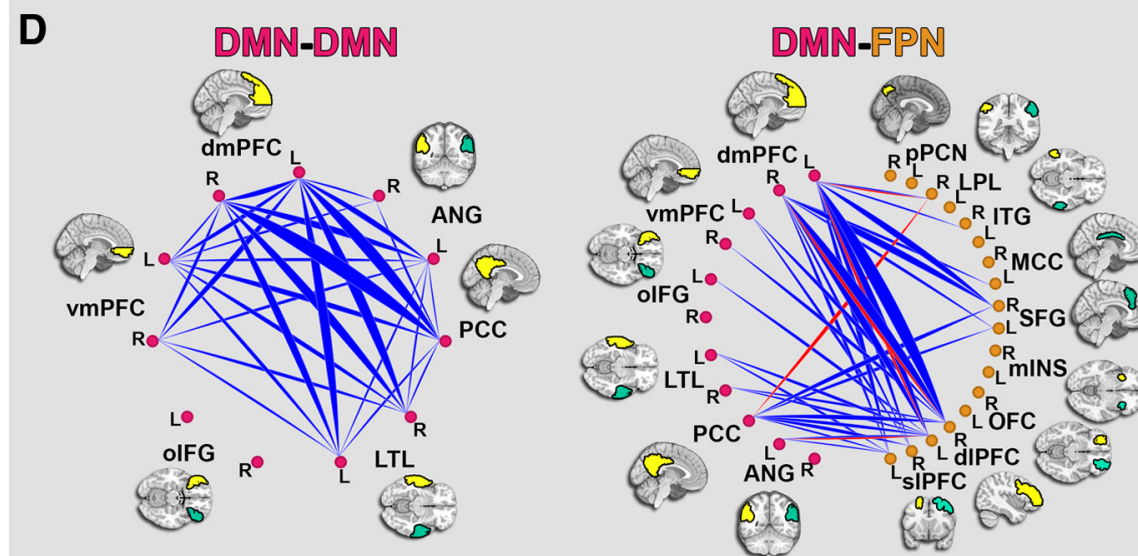

DMN-V/AN
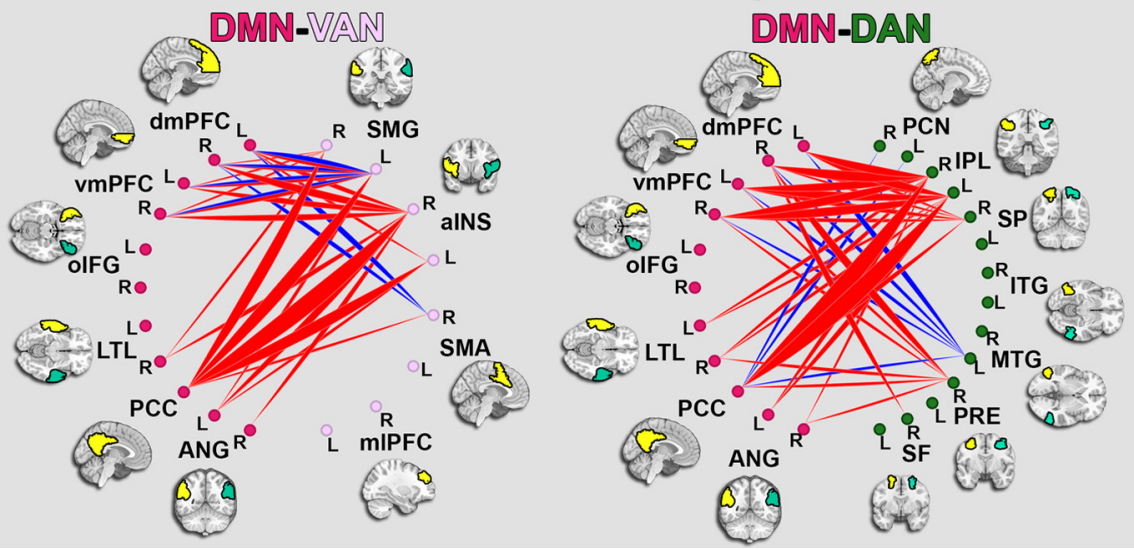

Figure 1. Component 1. Gray $(\boldsymbol{A})$ and white $(\boldsymbol{B})$ matter changes associated with the component. $\boldsymbol{C}$, Abnormal connections among cortical ROIs within seven large-scale networks. $\boldsymbol{D}$, Circle graphs more finely examine abnormal internetwork relationships from $\boldsymbol{C}$. Abbreviations for all networks and subregions are listed in Tables 2 and 3. This multimodal component reveals decreased segregation between DMN and TPNs that co-occurs with structural deficits in cognitive control regions, including dACC and dIPFC.

note, ordering of components in ICA is arbitrary). For each component's connectomic pattern, as well as selected circle graphs for particular network pairs of interest, along with selected slices of gray and white matter differences, see Figures 1, 2, 3, and 4. Tables 2 and 3 list abbreviations used throughout figures. Cluster and peak information for gray and white matter changes, labeled according to AAL atlas (Tzourio-Mazoyer et al., 2002) and JHU atlas (Hua et al., 2008), for each component are reported in Tables 4, 5, 6, and 7. Abbreviations used in these tables are listed in Table 8 .

\section{Component 1 showed reduced DMN-TPN segregation and structural alterations in cognitive regulation regions}

Component 1 (Fig. 1) exhibited a prominent decrease in intraDMN connectivity as well as increased DMN-DAN connectivity, 
A
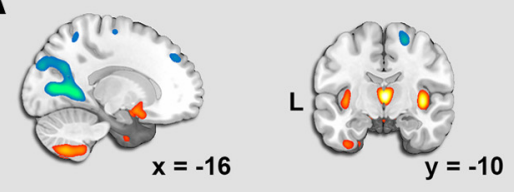

B

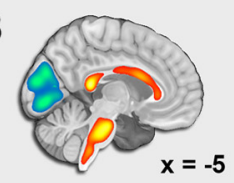

$-5$ $x=-5$

D
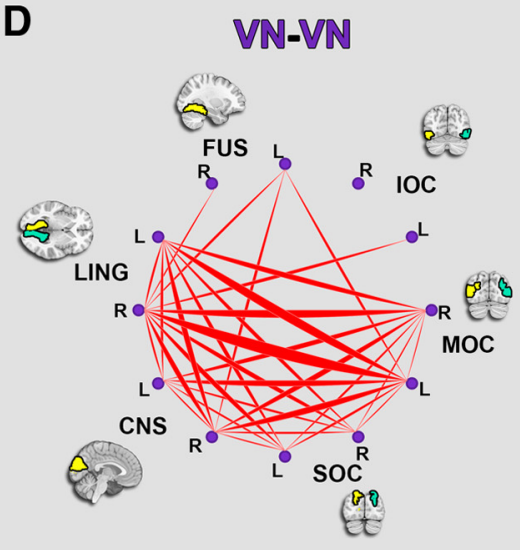
Z score
C

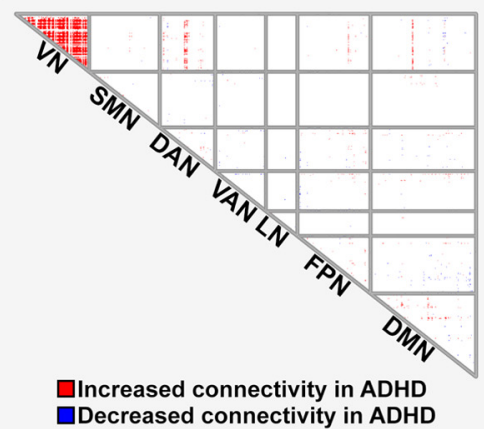

VN-DAN

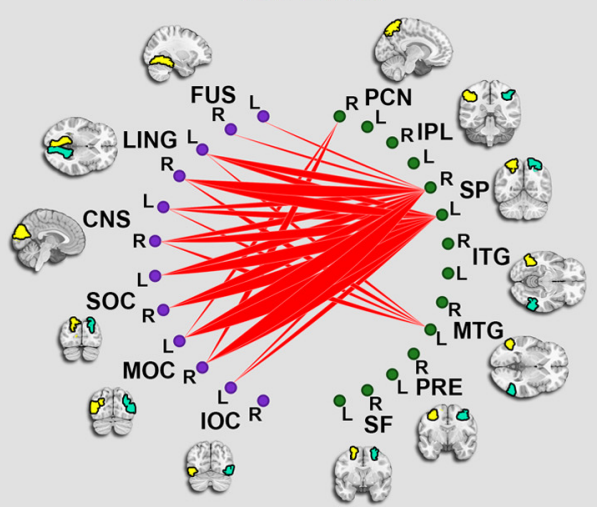

Figure 2. Component 4. Gray $(\boldsymbol{A})$ and white $(\boldsymbol{B})$ matter changes associated with the component. $\boldsymbol{C}$, Abnormal connections among cortical ROIs within seven large-scale networks. $\boldsymbol{D}$, Circle graphs more finely examine abnormal internetwork relationships from C. Abbreviations for all networks and subregions are listed in Tables 2 and 3. This multimodal component reveals hyperconnectivity within VN that co-occurs with diffuse reduced white and gray matter throughout visual cortex.

insula, and inferior and right superior cerebellum, and white matter increases in mid to anterior corpus callosum, left inferior operculum, and brainstem. See Table 5 for cluster and peak information for gray and white matter changes in Component 4.

Component 9 (Fig. 3) was marked by decreased connectivity both within DAN and in DAN-VN and DAN-somatomotor network (SMN). Within DAN, precuneal cortices (bilaterally, though most markedly on the left) and right superior occipital areas experienced decreased gray matter volume. In addition, there were gray matter increases in temporal pole and decreased gray matter in inferior cerebellar regions. See Table 6 for cluster and peak information for gray and white matter changes in Component 9.

\section{Component 12 showed prominent structural abnormalities in DMN} Component 12 (Fig. 4) showed robust gray matter reductions in regions of the brain within DMN, including ventromedial prefrontal cortex, PCC, lateral temporal pole, and middle temporal gyrus. Although the associated connectomic map was sparser than other components, nonetheless it showed some concentration in intra-FPN, as well as FPN-DAN, with FPN termini predominantly in sIPFC and dlPFC; and FPN-VAN, with FPN termini largely localized to dlPFC. In addi-

largely terminating in inferior parietal lobule (IPL) in DAN, and mostly increased DMN-VAN alterations, with strong participation by posterior cingulate cortex (PCC) in DMN. An additional post hoc analysis (see Materials and Methods) showed that most of these connections exhibited a pattern of decreased segregation (DMN-DAN: 81.7\%; DMN-VAN 65.3\%). There was also increased DMN-frontoparietal network (FPN) connectivity, dominated by altered connections involving superior lateral prefrontal cortex (slPFC) and dlPFC in FPN. The dlPFC (especially left dlPFC) was also a focal point of gray matter reductions, along with other cognitive control regions, including anterior cingulate cortex (ACC). In addition, there were gray matter decreases in bilateral temporal pole regions and white matter reductions in splenium, mid-corpus callosum, and brainstem. See Table 4 for cluster and peak information for gray and white matter changes in Component 1.

\section{Two components showed heavy involvement of visual network and dorsal attention network}

Component 4 (Fig. 2) exhibited widespread hyperconnectivity in connections within visual network (VN). There was also a pattern of hyperconnectivity between diverse regions of VN and DAN, with most DAN termini in superior parietal (SP) regions. Functional alterations involving the visual system were mirrored by bilaterally decreased gray matter volume along the anterior calcarine fissure near primary visual cortices and diffuse bilateral white matter decreases in posterior visual regions extending to extrastriate visual cortical areas. In addition, there was increased gray matter in the thalamus, ventral regions of striatum, bilateral tion, there were gray matter increases in thalamus and bilateral precentral regions whereas white matter alterations included increases in bilateral precentral areas and decreases in bilateral middle temporal gyrus. See Table 7 for cluster and peak information for gray and white matter changes in Component 12 .

\section{Components 4 and 12 were selectively predicted by}

inattention and hyperactivity/impulsivity scores, respectively Further investigation of the association between component expression and symptom severity scores proceeded on the subsample of 180 participants as described in Materials and Methods. This analysis revealed that Component 4 was significantly predicted by inattention $\left(t_{(170)}=2.07, p=0.04\right)$ whereas Component 12 was significantly predicted by hyperactivity/impulsivity $\left(t_{(170)}=2.45\right.$, $p=0.02$ ). In both cases, higher symptom severity scores were associated with increased component expression.

\section{For all four components, gray matter and functional} connectivity effects exhibited strong spatial correspondence Correlation tests were used to assess spatial correspondence between gray matter and functional connectivity impact scores. Using a simulation-based approach to assess statistical significance while accounting for spatial dependence (see Materials and Methods), we found that, for all four components, there were highly statistically significant positive correlations (Component $1: r=0.25, p<0.0001$; Component 4: $r=0.28, p<0.0001$; Component 9: $r=0.14, p=0.0047$; Component 12: $r=0.17, p=$ $0.0020)$, indicating that, as a component's impact on gray matter at a region increased, the impact on functional connectivity at 
that region also increased. Scatter plots of the correlated impact scores are shown in Figure 5.

\section{Discussion}

We investigated interrelationships between abnormalities seen in three types of neuroimaging-derived maps (resting state functional connectivity, gray matter volume, and white matter volume) using joint ICA, a multivariate, multimodal method. We found four modality-spanning components that are altered in ADHD that encompass (1) altered internetwork relations, in particular reduced segregation between DMN and TPNs, with co-occurring structural deficits in TPN regulatory nodes; and (2) abnormal intranetwork connectivity with co-occurring structural deficits in DMN, DAN, and VN. In addition, all four components showed spatial correspondence in the presence of gray matter changes and functional connectivity changes. These findings are highly consistent with an emerging ADHD literature that highlights the role of both alterations in distributed large-scale networks as well as focal deficits in cognitive and motoric regulation regions in ADHD (Castellanos et al., 2006). Moreover, the findings support the view that these functional and structural deficits are interconnected and covary across subjects. More tentatively, these results invite further investigation into avenues for combining multiple modalities to develop genuinely transmodal biomarkers of ADHD.

Influential network models of ADHD identify altered interrelationships between DMN and TPNs, in particular reduced suppression of DMN and reduced segregation between the networks, as a key locus of dysfunction in ADHD (Sonuga-Barke and Castellanos, 2007; Castellanos and Proal, 2012). In this study, we found both functional and structural evidence consistent with this model. Component 1 showed evidence of decreased segregation between DMN on the one hand and two major TPNs, DAN and VAN (Fig. 1). Component 1 also exhibited decreased gray mater volume spanning dorsal and rostral ACC. Dorsal ACC is implicated in conflict monitoring, is frequently found to be abnormal in ADHD (Bush et al., 1999; Bush, 2009), and has been linked to mechanisms by which psychostimulants improve attention functioning (Bush et al., 2008). Component 1 also exhibited gray matter deficits in dIPFC, a region important in cognitive control (MacDonald et al., 2000; Miller and Cohen, 2001) and that reliably exhibits deficits in ADHD (Dickstein et al., 2006; Christakou et al., 2013). It has been hypothesized that reduced segregation between DMN and TPNs observed in functional connectivity studies arises due to reduced regulation and inhibition of the DMN by key TPN nodes (Fassbender et al., 2009; Anticevic et al., 2012). The fact that diminished DMN-TPNs segregation and reduced gray mat-
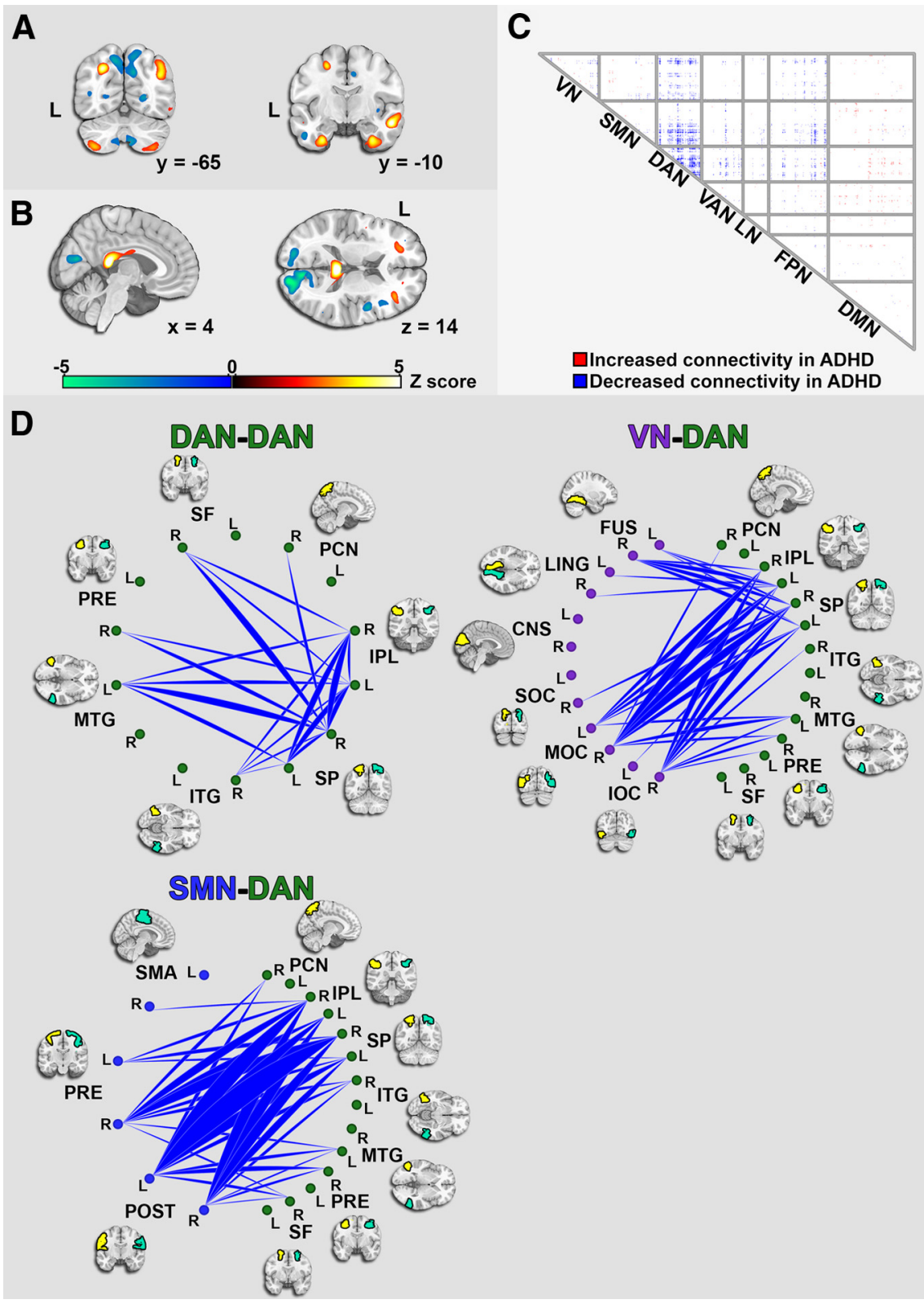

Figure 3. Component 9. Gray $(\boldsymbol{A})$ and white $(\boldsymbol{B})$ matter changes associated with the component. $\boldsymbol{C}$, Abnormal connections among cortical ROls within seven large-scale networks. $\boldsymbol{D}$, Circle graphs more finely examine abnormal internetwork relationships from C. Abbreviations for all networks and subregions are listed in Tables 2 and 3 . This multimodal component reveals structural abnormalities in DAN regions, including precuneus that co-occur with decreased intra-DAN connectivity.

ter in key TPN nodes load onto a common component provides additional evidence for this hypothesis.

In addition to deficits in the relations between DMN and TPNs, we also found deficits within individual ICNs. Component 1 exhibited dramatic hypoconnectivity within DMN (Fig. 1). This is consistent with recent reports using seed-based methods that found diminished connectivity between critical DMN hubs (Castellanos et al., 2008; Fair et al., 2010). Structural deficits in DMN, in particular diffuse reductions in gray matter in subgenual cingulate, PCC, and lateral temporal regions, were observed in Components 1 and 12. These findings of alterations within DMN are consistent with previous studies using other imaging metrics (Uddin et al., 2008; Tomasi and Volkow, 2012).

We observed functional alterations involving DAN in multiple ICA components. In Component 1 (Fig. 1), DAN exhibited 
A

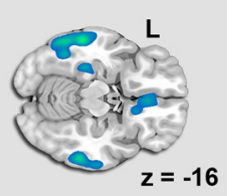

B
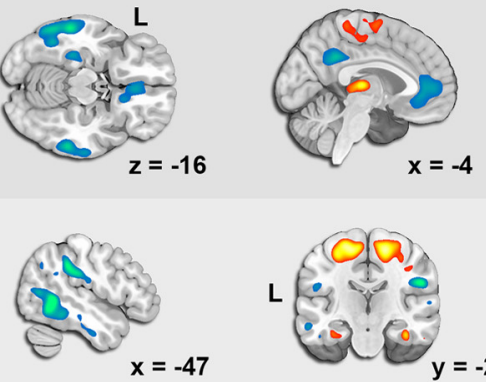

C

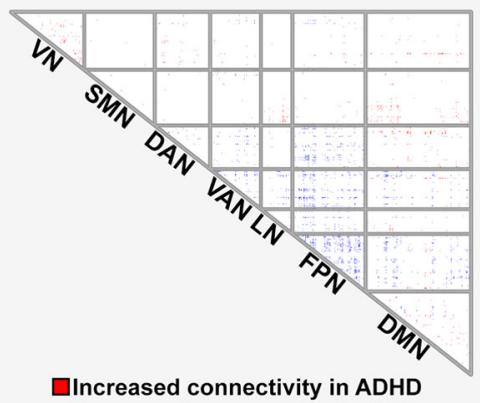

Increased connectivity in ADHD
Decreased connectivity in ADHD

\section{D}

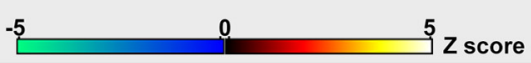
score
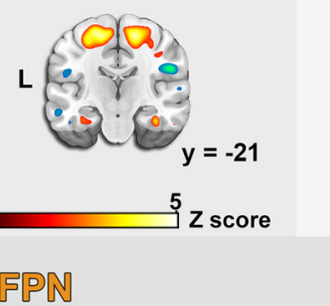

FPN-DAN

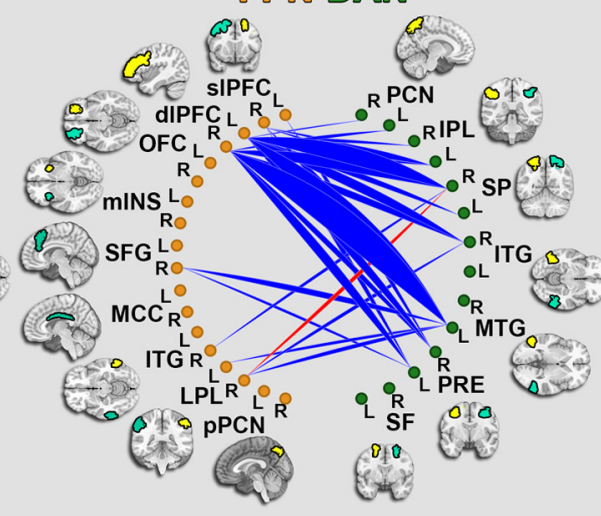

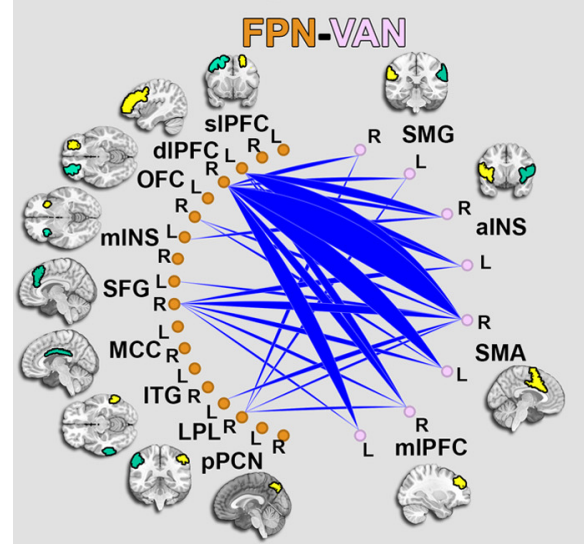

Figure 4. Component 12. Gray $(\boldsymbol{A})$ and white $(\boldsymbol{B})$ matter changes associated with the component. $\boldsymbol{C}$, Abnormal connections among cortical ROIs within seven large-scale networks. $\boldsymbol{D}$, Circle graphs more finely examine abnormal internetwork relationships from C. Abbreviations for all networks and subregions are listed in Tables 2 and 3 . This multimodal component shows reduced gray matter throughout DMN along with decreased connectivity within FPN, as well as between FPN and the dorsal and ventral attention networks, respectively.

decreased segregation with DMN. This was earlier explained in terms of the role of DAN, and other TPNs, in regulation and suppression of DMN during externally focused tasks. In Component 9 (Fig. 3), there was decreased connectivity within DAN and reduced connectivity between DAN and VN. DAN is richly interconnected with visual cortex, as demonstrated using convergent methods, including fMRI (Corbetta and Shulman, 2002), lesion studies (Corbetta and Shulman, 2011), transcranial magnetic stimulation (Ruff et al., 2006; Driver et al., 2010), and effective connectivity analysis (Vossel et al., 2012). Diminished DAN connections with $\mathrm{VN}$ might manifest as dysregulated visual attention and distractibility. This is consistent with our finding of altered VN connectivity in Component 4 (Fig. 2), which is discussed below. In Component 12 (Fig. 4), DAN regions, including bilat-

eral superior parietal cortex, exhibited diminished connectivity with key nodes of FPN, especially right and left dlPFC. FPN has been proposed to implement online adjustment of cognitive control (Dosenbach et al., 2007, 2008; Cole et al., 2013) and regulates DAN in accordance with goals and task demands (Gao and Lin, 2012; Spreng et al., 2010, 2013). Diminished FPN connectivity with DAN might thus contribute to the cognitive control deficits that are characteristic of ADHD (Douglas, 1999; Nigg, 2001). Together, our finding of distinct DAN deficits in three different ICA components suggests that DAN dysfunction is central to ADHD and additionally that ADHD might involve potentially separate and partially dissociable DAN-associated dysfunction.

We found strong evidence for linked structural and functional deficits in occipital regions associated with visual processing. Component 4 (Fig. 2) showed prominent VN hyperconnectivity, and there were overlapping gray and white matter alterations within regions of $\mathrm{VN}$, as well as structural alterations in related regions such as thalamus, which is implicated in visual attention (Saalmann and Kastner, 2011). Diminished coherence within VN (i.e., the opposite of what we found) has previously been demonstrated in states involving greater salience of external stimuli or heightened visual attention, including eyes open (vs eyes closed) rest (McAvoy et al., 2012), strong visual stimulation (Nauhaus et al., 2009), aversive pictures (relative to neutral ones) (Sripada et al., 2014a), and administration of alertness-enhancing compounds, such as methylphenidate (Sripada et al., 2013) and physostigmine (Ricciardi et al., 2013). Our finding of increased coherence within $\mathrm{VN}$ in ADHD could thus reflect diminished visual attention in the disorder, consistent with suggestions by other theorists (Castellanos and Proal, 2012).

In all four components, we found evidence of spatial co-occurrence of gray matter and functional connectivity effects; regions that showed greater gray matter changes also showed greater functional connectivity changes. Although there is a substantial literature in ADHD separately investigating gray matter disturbances and functional connectivity disturbances, to our knowledge, this is the first study that quantitatively identified spatial co-occurrence of these effects. This illustrates the utility of multimodal methodologies, such as jICA for delineating meaningful groups of interconnected findings distributed within and across modalities; in particular, the pattern of assortativity of these alterations can yield novel insights regarding disease pathophysiology.

Regarding the spatial co-occurrence of gray matter and functional connectivity changes, two possibilities are worth distinguishing. First, the spatial co-occurrence might be due to direct 

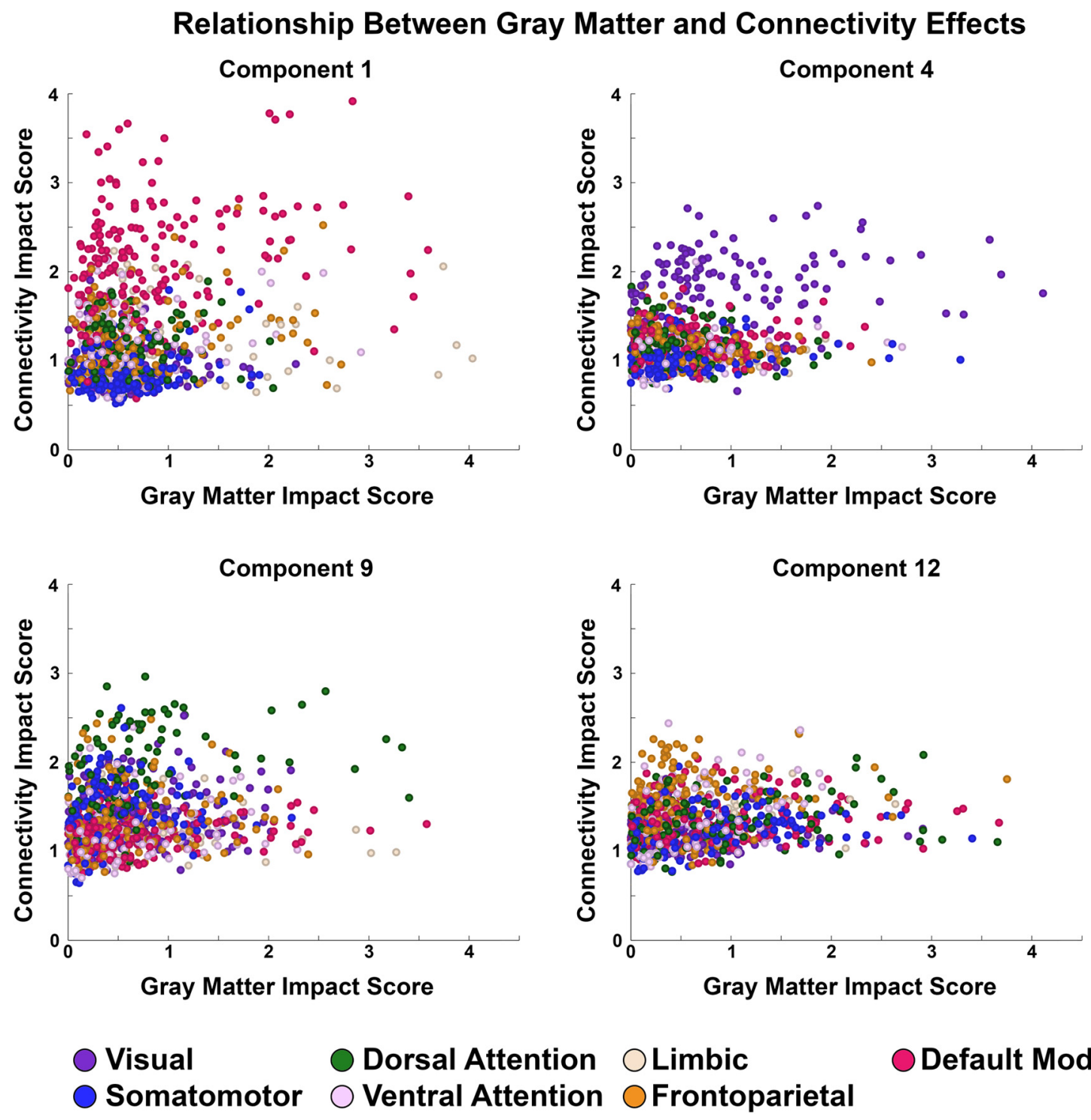

Figure 5. Relationship between functional connectivity impact score and gray matter impact score, paneled by component. Dots locate each ROl, colored based on network affiliation, with respect to gray matter changes (gray matter impact score) on $x$-axis and connectivity changes (connectivity impact score) on $y$-axis. All four components demonstrate a strong correspondence between gray matter and connectivity impact scores.

causal influences between structure and function. For example, primary disturbances in gray matter physiology, manifesting as volumetric changes, might produce changes in slow intrinsic oscillations of the affected tissue, which in turn impacts functional connectivity patterns. Alternatively, both structural and functional abnormalities might have a single "upstream" developmental common cause that produces both changes. Of note, this second explanation is not limited to accounting for effects within a component that are spatially co-occurring, it can also explain spatially disparate structural and functional connectivity changes as well (e.g., our finding in Component 1 of reduced DMN-TPN segregation along with structural alterations in cognitive regulation regions). During normal maturation from late childhood through early adulthood, DMN and TPNs segregate (Fair et al., 2007, 2008, 2010; Anderson et al., 2011) whereas gray matter in cognitive regulation regions undergoes a complex pattern of modulation (Giedd et al., 1999; Shaw et al., 2006). Any insult that produces a delay in normal developmental trajectories would thus produce reduced segregation between DMN and TPNs and could also impact gray matter in cognitive regulation regions, thus explaining the co-occurrence of these findings in Component 1 . In separate reports using this same dataset, we provide additional evidence for reduced segregation of DMN with VAN in ADHD (using an entirely different non-ICA-based methodology) (Sripada et al., 2014b). In addition, we demonstrate lag in typical maturational trajectories of connections within DMN and between DMN and TPNs (Sripada et al., 2014c).

We found differential loading of components onto distinct dimensional aspects of the ADHD phenotype. In particular, using Conners' symptom severity scores, we found that Component 4 was differentially predictive of greater inattentiveness. This finding fits well with our previously discussed hypothesis that alterations in Component 4 reflect perturbations in visual attention and attributions of visual salience. Component 12 was specifically related to hyperactivity/impulsivity. This might be related to the prominence of FPN, a network known to be involved in cognitive control (Dosenbach et al., 2007, 2008; Cole et al., 2013), in this component. These findings suggest that distinct 
dimensional aspects of ADHD exhibit dissociable transmodal signatures. The remaining two components (i.e., 1 and 9) were altered in ADHD (considered as a dichotomous diagnosis) but did not show specificity for the inattention or hyperactivity symptom dimensions. Future work using more refined symptom scales, as well as methods that directly probe selected symptom dimensions, such as task-based fMRI, could further elaborate these possibilities.

In conclusion, this is the first study to use multivariate, multimodal methodology to investigate linked structural and functional deficits in ADHD. We demonstrate transmodal deficits in ADHD that encompass functional relationships within and between large-scale networks and structural deficits in regions involved in cognitive control, with clear evidence of spatial cooccurrence of alterations in structure and function.

\section{Notes}

Supplemental material for this article is available at http://sites.lsa. umich.edu/sripada/data/. We provide unthresholded gray and white matter maps and additional details on our network subparcellation. This material has not been peer reviewed.

\section{References}

Abou-Elseoud A, Starck T, Remes J, Nikkinen J, Tervonen O, Kiviniemi V (2010) The effect of model order selection in group PICA. Hum Brain Mapp 31:1207-1216. CrossRef Medline

Anderson JS, Ferguson MA, Lopez-Larson M, Yurgelun-Todd D (2011) Connectivity gradients between the default mode and attention control networks. Brain Connect 1:147-157. CrossRef Medline

Anticevic A, Cole MW, Murray JD, Corlett PR, Wang XJ, Krystal JH (2012) The role of default network deactivation in cognition and disease. Trends Cogn Sci 16:584-592. CrossRef Medline

Ashburner J (2007) A fast diffeomorphic image registration algorithm. Neuroimage 38:95-113. CrossRef Medline

Behzadi Y, Restom K, Liau J, Liu TT (2007) A component based noise correction method (CompCor) for BOLD and perfusion based fMRI. Neuroimage 37:90-101. CrossRef Medline

Benjamini Y, Hochberg Y (1995) Controlling the false discovery rate: a practical and powerful approach to multiple testing. J R Stat Soc Ser B Methodol 57:289-300.

Buckner RL, Andrews-Hanna JR, Schacter DL (2008) The brain's default network. Ann N Y Acad Sci 1124:1-38. CrossRef Medline

Bush G (2009) Dorsal anterior midcingulate cortex: roles in normal cognition and disruption in attention-deficit/hyperactivity disorder. In: Cingulate neurobiology and disease (Vogt B, ed), pp 246-268. Oxford, United Kingdom: Oxford UP.

Bush G, Frazier JA, Rauch SL, Seidman LJ, Whalen PJ, Jenike MA, Rosen BR, Biederman J (1999) Anterior cingulate cortex dysfunction in attentiondeficit/hyperactivity disorder revealed by fMRI and the Counting Stroop. Biol Psychiatry 45:1542-1552. CrossRef Medline

Bush G, Spencer TJ, Holmes J, Shin LM, Valera EM, Seidman LJ, Makris N, Surman C, Aleardi M, Mick E, Biederman J (2008) Functional magnetic resonance imaging of methylphenidate and placebo in attention-deficit/ hyperactivity disorder during the multi-source interference task. Arch Gen Psychiatry 65:102-114. CrossRef Medline

Calhoun VD, Adali T, Giuliani NR, Pekar JJ, Kiehl KA, Pearlson GD (2006a) Method for multimodal analysis of independent source differences in schizophrenia: combining gray matter structural and auditory oddball functional data. Hum Brain Mapp 27:47-62. CrossRef Medline

Calhoun VD, Adali T, Kiehl KA, Astur R, Pekar JJ, Pearlson GD (2006b) A method for multitask fMRI data fusion applied to schizophrenia. Hum Brain Mapp 27:598-610. CrossRef Medline

Calhoun VD, Liu J, Adali T (2009) A review of group ICA for fMRI data and ICA for joint inference of imaging, genetic, and ERP data. Neuroimage 45:S163-S172. CrossRef Medline

Castellanos FX, Proal E (2012) Large-scale brain systems in ADHD: beyond the prefrontal-striatal model. Trends Cogn Sci 16:17-26. CrossRef Medline

Castellanos FX, Sonuga-Barke EJ, Milham MP, Tannock R (2006) Characterizing cognition in ADHD: beyond executive dysfunction. Trends Cogn Sci 10:117-123. CrossRef Medline
Castellanos FX, Margulies DS, Kelly C, Uddin LQ, Ghaffari M, Kirsch A, Shaw D, Shehzad Z, Di Martino A, Biswal B, Sonuga-Barke EJ, Rotrosen J, Adler LA, Milham MP (2008) Cingulate-precuneus interactions: a new locus of dysfunction in adult attention-deficit/hyperactivity disorder. Biol Psychiatry 63:332-337. CrossRef Medline

Christakou A, Murphy CM, Chantiluke K, Cubillo AI, Smith AB, Giampietro V, Daly E, Ecker C, Robertson D, Murphy DG, Rubia K (2013) Disorder-specific functional abnormalities during sustained attention in youth with Attention Deficit Hyperactivity Disorder (ADHD) and with Autism. Mol Psychiatry 18:236-244. CrossRef Medline

Cole MW, Reynolds JR, Power JD, Repovs G, Anticevic A, Braver TS (2013) Multi-task connectivity reveals flexible hubs for adaptive task control. Nat Neurosci 16:1348-1355. CrossRef Medline

Conners CK, Sitarenios G, Parker JD, Epstein JN (1998) The Revised Conners' Parent Rating Scale (CPRS-R): factor structure, reliability, and criterion validity. J Abnorm Child Psychol 26:257-268. CrossRef Medline

Corbetta M, Shulman GL (2002) Control of goal-directed and stimulus-driven attention in the brain. Nat Rev Neurosci 3:201-215. CrossRef Medline

Corbetta M, Shulman GL (2011) Spatial neglect and attention networks. Annu Rev Neurosci 34:569-599. CrossRef Medline

Cortese S, Kelly C, Chabernaud C, Proal E, Di Martino A, Milham MP, Castellanos FX (2012) Toward systems neuroscience of ADHD: a meta-analysis of 55 fMRI studies. Am J Psychiatry 169:1038-1055. CrossRef Medline

Dickstein SG, Bannon K, Castellanos FX, Milham MP (2006) The neural correlates of attention deficit hyperactivity disorder: an ALE metaanalysis. J Child Psychol Psychiatry 47:1051-1062. CrossRef Medline

Di Martino A, Zuo XN, Kelly C, Grzadzinski R, Mennes M, Schvarcz A, Rodman J, Lord C, Castellanos FX, Milham MP (2013) Shared and distinct intrinsic functional network centrality in autism and attention-deficit/hyperactivity disorder. Biol Psychiatry 74:623-632. CrossRef Medline

Dosenbach NU, Fair DA, Miezin FM, Cohen AL, Wenger KK, Dosenbach RA, Fox MD, Snyder AZ, Vincent JL, Raichle ME, Schlaggar BL, Petersen SE (2007) Distinct brain networks for adaptive and stable task control in humans. Proc Natl Acad Sci U S A 104:11073-11078. CrossRef Medline

Dosenbach NU, Fair DA, Cohen AL, Schlaggar BL, Petersen SE (2008) A dual-networks architecture of top-down control. Trends Cogn Sci 12:99_ 105. CrossRef Medline

Douglas VI (1999) Cognitive control processes in attention-deficit/hyperactivity disorder. In: Handbook of disruptive behavior disorders (Quay HC, Hogan AE, eds), pp 105-138. Dordrecht, The Netherlands: Kluwer Academic.

Driver J, Blankenburg F, Bestmann S, Ruff CC (2010) New approaches to the study of human brain networks underlying spatial attention and related processes. Exp Brain Res 206:153-162. CrossRef Medline

Fair DA, Dosenbach NU, Church JA, Cohen AL, Brahmbhatt S, Miezin FM, Barch DM, Raichle ME, Petersen SE, Schlaggar BL (2007) Development of distinct control networks through segregation and integration. Proc Natl Acad Sci U S A 104:13507-13512. CrossRef Medline

Fair DA, Cohen AL, Dosenbach NU, Church JA, Miezin FM, Barch DM, Raichle ME, Petersen SE, Schlaggar BL (2008) The maturing architecture of the brain's default network. Proc Natl Acad Sci U S A 105:40284032. CrossRef Medline

Fair DA, Posner J, Nagel BJ, Bathula D, Dias TG, Mills KL, Blythe MS, Giwa A, Schmitt CF, Nigg JT (2010) Atypical default network connectivity in youth with attention-deficit/hyperactivity disorder. Biol Psychiatry 68: 1084-1091. CrossRef Medline

Fair DA, Nigg JT, Iyer S, Bathula D, Mills KL, Dosenbach NU, Schlaggar BL, Mennes M, Gutman D, Bangaru S, Buitelaar JK, Dickstein DP, Di Martino A, Kennedy DN, Kelly C, Luna B, Schweitzer JB, Velanova K, Wang YF, Mostofsky S, et al. (2013) Distinct neural signatures detected for ADHD subtypes after controlling for micro-movements in resting state functional connectivity MRI data. Front Syst Neurosci 6:80. Medline

Fassbender C, Zhang H, Buzy WM, Cortes CR, Mizuiri D, Beckett L, Schweitzer JB (2009) A lack of default network suppression is linked to increased distractibility in ADHD. Brain Res 1273:114-128. CrossRef Medline

Fox MD, Snyder AZ, Vincent JL, Corbetta M, Van Essen DC, Raichle ME (2005) The human brain is intrinsically organized into dynamic, anticorrelated functional networks. Proc Natl Acad Sci U S A 102:9673-9678. CrossRef Medline

Gao W, Lin W (2012) Frontal parietal control network regulates the anticorrelated default and dorsal attention networks. Hum Brain Mapp 33: 192-202. CrossRef Medline

Giedd JN, Blumenthal J, Jeffries NO, Castellanos FX, Liu H, Zijdenbos A, Paus T, 
Evans AC, Rapoport JL (1999) Brain development during childhood and adolescence: a longitudinal MRI study. Nat Neurosci 2:861-863. CrossRef Medline

Himberg J, Hyvärinen A, Esposito F (2004) Validating the independent components of neuroimaging time-series via clustering and visualization. Neuroimage 22:1214-1222. CrossRef Medline

Hua K, Zhang J, Wakana S, Jiang H, Li X, Reich DS, Calabresi PA, Pekar JJ, van Zijl PC, Mori S (2008) Tract probability maps in stereotaxic spaces: analyses of white matter anatomy and tract-specific quantification. Neuroimage 39:336-347. CrossRef Medline

Hyvärinen A (1999) Fast and robust fixed-point algorithms for independent component analysis. IEEE Trans Neural Netw 10:626-634. CrossRef Medline

Kao GS, Thomas HM (2010) Test review: C. Keith Conners "Conners 3rd Edition” Toronto, Ontario, Canada-Multi-Health Systems, 2008. J Psychoeduc Assess 28:598-602. CrossRef

Kelly AM, Uddin LQ, Biswal BB, Castellanos FX, Milham MP (2008) Competition between functional brain networks mediates behavioral variability. Neuroimage 39:527-537. CrossRef Medline

Khadka S, Meda SA, Stevens MC, Glahn DC, Calhoun VD, Sweeney JA, Tamminga CA, Keshavan MS, O’Neil K, Schretlen D, Pearlson GD (2013) Is aberrant functional connectivity a psychosis endophenotype? A resting state functional magnetic resonance imaging study. Biol Psychiatry 74:458-466. CrossRef Medline

MacDonald AW 3rd, Cohen JD, Stenger VA, Carter CS (2000) Dissociating the role of the dorsolateral prefrontal and anterior cingulate cortex in cognitive control. Science 288:1835-1838. CrossRef Medline

Makris N, Biederman J, Valera EM, Bush G, Kaiser J, Kennedy DN, Caviness VS, Faraone SV, Seidman LJ (2007) Cortical thinning of the attention and executive function networks in adults with attention-deficit/hyperactivity disorder. Cereb Cortex 17:1364-1375. CrossRef Medline

McAvoy M, Larson-Prior L, Ludwikow M, Zhang D, Snyder AZ, Gusnard DL, Raichle ME, d'Avossa G (2012) Dissociated mean and functional connectivity BOLD signals in visual cortex during eyes closed and fixation. J Neurophysiol 108:2363-2372. CrossRef Medline

Miller EK, Cohen JD (2001) An integrative theory of prefrontal cortex function. Annu Rev Neurosci 24:167-202. CrossRef Medline

Nauhaus I, Busse L, Carandini M, Ringach DL (2009) Stimulus contrast modulates functional connectivity in visual cortex. Nat Neurosci 12:70-76. CrossRef Medline

Nigg JT (2001) Is ADHD a disinhibitory disorder? Psychol Bull 127:571598. CrossRef Medline

Pironti VA, Lai MC, Müller U, Dodds CM, Suckling J, Bullmore ET, Sahakian BJ (2014) Neuroanatomical abnormalities and cognitive impairments are shared by adults with attention-deficit/hyperactivity disorder and their unaffected firstdegree relatives. Biol Psychiatry 76:639-647. CrossRef Medline

Power JD, Cohen AL, Nelson SM, Wig GS, Barnes KA, Church JA, Vogel AC, Laumann TO, Miezin FM, Schlaggar BL, Petersen SE (2011) Functional network organization of the human brain. Neuron 72:665-678. CrossRef Medline

Raichle ME, MacLeod AM, Snyder AZ, Powers WJ, Gusnard DA, Shulman GL (2001) A default mode of brain function. Proc Natl Acad Sci U S A 98:676-682. CrossRef Medline

Ray KL, McKay DR, Fox PM, Riedel MC, Uecker AM, Beckmann CF, Smith SM, Fox PT, Laird AR (2013) ICA model order selection of task coactivation networks. Front Neurosci 7:1-12. CrossRef Medline

Ray S, Miller M, Karalunas S, Robertson C, Grayson DS, Cary RP, Hawkey E, Painter JG, Kriz D, Fombonne E, Nigg JT, Fair DA (2014) Structural and functional connectivity of the human brain in autism spectrum disorders and attention-deficit/hyperactivity disorder: a rich club-organization study. Hum Brain Mapp. Advance online publication. Retrieved Aug. 13, 2014. doi: 10.1002/hbm.22603. CrossRef Medline

Ricciardi E, Handjaras G, Bernardi G, Pietrini P, Furey ML (2013) Cholinergic enhancement reduces functional connectivity and BOLD variability in visual extrastriate cortex during selective attention. Neuropharmacology 64:305-313. CrossRef Medline

Ruff CC, Blankenburg F, Bjoertomt O, Bestmann S, Freeman E, Haynes JD, Rees G, Josephs O, Deichmann R, Driver J (2006) Concurrent TMSfMRI and psychophysics reveal frontal influences on human retinotopic visual cortex. Curr Biol 16:1479-1488. CrossRef Medline

Saalmann YB, Kastner S (2011) Cognitive and perceptual functions of the visual thalamus. Neuron 71:209-223. CrossRef Medline

Seidman LJ, Valera EM, Makris N (2005) Structural brain imaging of atten- tion-deficit/hyperactivity disorder. Biol Psychiatry 57:1263-1272. CrossRef Medline

Seidman LJ, Valera EM, Makris N, Monuteaux MC, Boriel DL, Kelkar K, Kennedy DN, Caviness VS, Bush G, Aleardi M, Faraone SV, Biederman J (2006) Dorsolateral prefrontal and anterior cingulate cortex volumetric abnormalities in adults with attention-deficit/hyperactivity disorder identified by magnetic resonance imaging. Biol Psychiatry 60:1071-1080. CrossRef Medline

Shaw P, Greenstein D, Lerch J, Clasen L, Lenroot R, Gogtay N, Evans A, Rapoport J, Giedd J (2006) Intellectual ability and cortical development in children and adolescents. Nature 440:676-679. CrossRef Medline

Shaw P, Eckstrand K, Sharp W, Blumenthal J, Lerch JP, Greenstein D, Clasen L, Evans A, Giedd J, Rapoport JL (2007) Attention-deficit/hyperactivity disorder is characterized by a delay in cortical maturation. Proc Natl Acad Sci U S A 104:19649-19654. CrossRef Medline

Sonuga-Barke EJ, Castellanos FX (2007) Spontaneous attentional fluctuations in impaired states and pathological conditions: a neurobiological hypothesis. Neurosci Biobehav Rev 31:977-986. CrossRef Medline

Spreng RN, Stevens WD, Chamberlain JP, Gilmore AW, Schacter DL (2010) Default network activity, coupled with the frontoparietal control network, supports goal-directed cognition. Neuroimage 53:303-317. CrossRef Medline

Spreng RN, Sepulcre J, Turner GR, Stevens WD, Schacter DL (2013) Intrinsic architecture underlying the relations among the default, dorsal attention, and frontoparietal control networks of the human brain. J Cogn Neurosci 25:74-86. CrossRef Medline

Sripada C, Kessler D, Welsh R, Angstadt M, Liberzon I, Phan KL, Scott C (2013) Distributed effects of methylphenidate on the network structure of the resting brain: a connectomic pattern classification analysis. Neuroimage 11:213-221. CrossRef Medline

Sripada C, Angstadt M, Kessler D, Phan KL, Liberzon I, Evans GW, Welsh RC, Kim P, Swain JE (2014a) Volitional regulation of emotions produces distributed alterations in connectivity between visual, attention control, and default networks. Neuroimage 89:110-121. CrossRef Medline

Sripada C, Kessler D, Fang Y, Welsh RC, Prem Kumar K, Angstadt M (2014b) Disrupted network architecture of the resting brain in attention-deficit/hyperactivity disorder. Hum Brain Mapp 35:4693-4705. CrossRef Medline

Sripada CS, Kessler D, Angstadt M (2014c) Lag in maturation of the brain's intrinsic functional architecture in attention-deficit/hyperactivity disorder. Proc Natl Acad Sci U S A 111:14259-14264. CrossRef Medline

Sui J, Pearlson G, Caprihan A, Adali T, Kiehl KA, Liu J, Yamamoto J, Calhoun VD (2011) Discriminating schizophrenia and bipolar disorder by fusing fMRI and DTI in a multimodal CCA ${ }^{+}$joint ICA model. Neuroimage 57:839-855. CrossRef Medline

Tian L, Jiang T, Wang Y, Zang Y, He Y, Liang M, Sui M, Cao Q, Hu S, Peng M, Zhuo Y (2006) Altered resting-state functional connectivity patterns of anterior cingulate cortex in adolescents with attention deficit hyperactivity disorder. Neurosci Lett 400:39-43. CrossRef Medline

Tomasi D, Volkow ND (2012) Abnormal functional connectivity in children with attention-deficit/hyperactivity disorder. Biol Psychiatry 71: 443-450. CrossRef Medline

Tzourio-Mazoyer N, Landeau B, Papathanassiou D, Crivello F, Etard O, Delcroix N, Mazoyer B, Joliot M (2002) Automated anatomical labeling of activations in SPM using a macroscopic anatomical parcellation of the MNI MRI single-subject brain. Neuroimage 15:273-289. CrossRef Medline

Uddin LQ, Kelly AM, Biswal BB, Margulies DS, Shehzad Z, Shaw D, Ghaffari M, Rotrosen J, Adler LA, Castellanos FX, Milham MP (2008) Network homogeneity reveals decreased integrity of default-mode network in ADHD. J Neurosci Methods 169:249-254. CrossRef Medline

Vossel S, Weidner R, Driver J, Friston KJ, Fink GR (2012) Deconstructing the architecture of dorsal and ventral attention systems with dynamic causal modeling. J Neurosci Off J Soc Neurosci 32:10637-10648. CrossRef Medline

Watanabe T, Kessler D, Scott C, Angstadt M, Sripada C (2014) Disease prediction based on functional connectomes using a scalable and spatially-informed support vector machine. Neuroimage 96:183-202. CrossRef Medline

Weissman DH, Roberts KC, Visscher KM, Woldorff MG (2006) The neural bases of momentary lapses in attention. Nat Neurosci 9:971-978. CrossRef Medline

Yeo BT, Krienen FM, Sepulcre J, Sabuncu MR, Lashkari D, Hollinshead M, Roffman JL, Smoller JW, Zöllei L, Polimeni JR, Fischl B, Liu H, Buckner RL (2011) The organization of the human cerebral cortex estimated by intrinsic functional connectivity. J Neurophysiol 106:1125-1165. CrossRef Medline 